\title{
Risks to Healthcare Organizations and Staff Who Manage Obese (Bariatric) Patients and Use of Obesity Data to Mitigate Risks: A Literature Review
}

This article was published in the following Dove Press journal:

Journal of Multidisciplinary Healthcare

\section{Kim McClean (ID) \\ Martyn Cross $(\mathbb{D}$ \\ Sue Reed (D)}

School of Medical and Health Sciences, Edith Cowan University, Western

Australia, 6027, Australia
Correspondence: Kim McClean Occupational Safety and Health Department at Edith Cowan University, Western Australia, 6027, Australia

Tel +6I 863045764

Fax+6I 863042626

Email k.mcclean@ecu.edu.au

\begin{abstract}
This literature review explores obesity risks to healthcare staff and organizations that manage and caring for obese (bariatric) patients. These risks are anticipated to increase due to Australian population obesity rate projections increasing from $31 \%$ in 2018 to $42 \%$ by the year 2035, which will result in increased hospital admissions of patients with obesity. Literature searches were conducted through the Cumulative Index to Nursing and Allied Health Literature (CINAHL), MEDLINE, Scopus, and Web of Science. Thirty studies met the inclusion criteria and were tabulated and critiqued using appropriate appraisal techniques. High risk of injury to healthcare staff was identified relating to bariatric patient handling tasks. High liability and financial risks of organizations were also identified relating to workers' compensation and common law claims by injured staff and medical negligence claims by patients with obesity. Availability of obesity data was identified within clinically captured information, which could be utilized to inform obesity risk management programs. Future research should focus on improving the use and quality of obesity data to better understand obesity risks to healthcare organizations and staff, including accurate identification of obese patient admissions, enhanced ability to measure bariatric patient handling hazards and related staff injuries and improved assessment of bariatric intervention effectiveness.
\end{abstract}

Keywords: hospital, patient handling, injury, risk management, body mass index, patient

\section{Introduction}

Staff employed in industries such as healthcare, aged care, emergency services and funeral homes may be at risk of injuries due to the impacts of obesity. Increasing population obesity is recognized worldwide, with the World Health Organization (WHO) defining obesity as one of the world's most significant health problems. ${ }^{1}$ The Australian Bureau of Statistics' (ABS) Australian Health Survey 2017-18 revealed that $67 \%$ of Australian adults were overweight or obese in 2017-18, comprising $30.8 \%$ obese and $35.6 \%$ overweight. $^{2}$ This is an increase from $63.4 \%$ in 2014-15 and $62.8 \%$ in 2011-12. Worryingly, Australian obesity projections predict in $2035,42 \%$ of the population will be obese and $35 \%$ will be overweight. ${ }^{3}$

Increases in population obesity rates correlate with increases in patients with obesity requiring care, and future risks of patient handling injuries to nurses and other healthcare staff will be considerable. ${ }^{4}$ A number of sources have also 
demonstrated that patients with obesity have an increased likelihood of requiring medical intervention than patients who are within healthy weight ranges. ${ }^{5-8}$ Additionally, increasing trends of bariatric surgery for weight loss contribute to the increasing obese patient population in hospitals.

Staff working in hospitals, nursing homes, emergency services and funeral homes are required to handle and move clients or patients with obesity, also referred to as bariatric patients. In the aged care and hospital environments these tasks are generally conducted by nurses and patient care staff and include lifting, turning and repositioning patients, bathing tasks, making occupied beds, standing patients, conducting patient transfers, and changing dressings. ${ }^{9}$ These tasks often cannot be conducted using standard manual handling practices as the patient's weight is unevenly distributed, can be bulky or asymmetrical and cannot be held close to the nurse/patient care staff..$^{10}$ Additionally, the risks to carers will vary due to the patient's mobility, uncooperative behavior or sudden loss of balance.

Healthcare workers experience one of the highest rates of musculoskeletal disorders (MSD) worldwide, with $46 \%$ of nursing assistants reporting hurting themselves while lifting, moving or helping a patient and $40 \%$ reporting a back injury due to conducting these tasks. ${ }^{11,12}$ Furthermore, $20 \%$ of nurses experience work-related pain on any given day, and $50 \%$ of staff consider leaving nursing because of the physical stress and injury involved. ${ }^{13}$ Fear of injuries when moving patients with obesity is also a major concern of nurses and may affect an organization's ability to attract and retain staff. ${ }^{14}$ It is clear that increasing population obesity also increases risks of workplace injuries in healthcare environments due to more patients with obesity attending hospitals for treatment.

Healthcare organizations have both moral and legal obligations to manage obesity risks to their employees and patients. When risks are identified, risk management approaches including the use of available data must be adopted to decrease risks as far as reasonably practicable. A number of studies have independently identified increasing risks of obesity in the Australian population, obesityrelated risks to healthcare workers conducting patient handling tasks, legal and workers' compensation cases due to healthcare injuries and use of healthcare data to mitigate risks; however, there is a lack of understanding and connectivity to define the impact of obesity-related risks to healthcare organizations and staff. Consolidating resources and comprehensively understanding risks relating to the care of patients with obesity and the availability of obesity data to mitigate risks is warranted, particularly to improve safety outcomes for both healthcare workers and patients, and reducing risks for healthcare organizations. This literature review has examined worldwide studies that focus on risks to healthcare organizations and staff who manage patients with obesity and explores the ability to identify and quantify bariatric risks by using available data. The review includes an expansive and holistic examination of obesity-related risks and enhanced use of data to potentially reduce risks, which is a unique review approach not available in the current literature.

\section{Materials and Methods Data Sources and Search Strategies}

A systematic search was conducted to synthesize the current literature on risks to hospitals, nurses and other healthcare staff who manage patients with obesity. Furthermore, risks involving patient handling tasks and the use of obese patient admission data as a potential method to inform risk mitigation strategies were examined. The PICoS statement in Table 1 was used to inform the search strategy.

The Search, AppraisaL, Synthesis and Analysis (SALSA) analytical framework was used to conduct the literature review, and searches were conducted for qualitative, quantitative and mixed-method literature published between 1999 and 2019 in the Cumulative Index to Nursing and Allied Health Literature (CINAHL), MEDLINE, Scopus, and Web of Science. Database searches for potentially relevant articles included combinations of terms displayed in Table 2.

\section{Inclusion and Exclusion Criteria}

To be considered for full review, papers were required to meet the following inclusion criteria: (i) include obesity

Table I Search PICoS Statement

\begin{tabular}{|l|l|}
\hline P (population) & Nurses, healthcare workers \\
\hline $\begin{array}{l}\text { I (phenomenon of } \\
\text { interest) }\end{array}$ & Obesity risks \\
\hline Co (context) & Hospitals \\
\hline S (study design) & $\begin{array}{l}\text { Qualitative, quantitative and mixed } \\
\text { method }\end{array}$ \\
\hline
\end{tabular}


Table 2 Medical Subject Heading (MeSH) and Keyword Terms for Literature Search

\begin{tabular}{|c|c|}
\hline $\begin{array}{l}\text { Search } \\
\text { Category }\end{array}$ & Search Terms Used \\
\hline $\begin{array}{l}\text { Healthcare } \\
\text { staff AND }\end{array}$ & Nurs* OR "healthcare staff" \\
\hline Obesity AND & $\begin{array}{l}\text { Bariatric OR obes* OR weight OR overweight OR } \\
\text { BMI or "body mass index" }\end{array}$ \\
\hline $\begin{array}{l}\text { Patient } \\
\text { handling OR }\end{array}$ & $\begin{array}{l}\text { "Patient handling" OR lifting OR transfer OR } \\
\text { "manual handling" OR "patient care" }\end{array}$ \\
\hline Injuries OR & Injur* \\
\hline Data & Data \\
\hline
\end{tabular}

Note: *Refers to truncation searching, enabling expanded searches for different forms of the word.

risks in a healthcare environment, (ii) reference at least one obesity-related risk such as patient handling or injuries or iii) reference use of obesity-related data and (iv) be published in English in a peer-reviewed journal. Grey literature and papers that related to obese healthcare staff or pediatric obesity were excluded.

\section{Identification of Relevant Studies and Data Extraction}

The principal author undertook the paper screenings from January 2018 to September 2020. Potential papers were first identified by screening the title and then by screening the abstract. Eligible papers were then assessed in full for consideration of inclusion in the review, and then, study particulars were extracted from the reviewed papers. Figure 1 demonstrates the PRISMA search strategy and synthesis.

\section{Outcomes of Literature Search}

The initial literature queries in CINAHL, MEDLINE, Scopus, and Web of Science databases cross-referenced 15 Medical Subject Heading (MeSH) terms or keyword identifiers as displayed in Table 2 and produced 3181 compiled results. A review of the limiters and duplicated records excluded 2193 records from the study. The study exclusion criteria were applied, and titles were screened for relevance, resulting in 822 records being excluded. A further review of abstracts was conducted to refine the results, and a total of 92 did not meet the study protocols and were removed. Finally, the 74 remaining studies were further scrutinized against the review inclusion criteria and
44 were removed due to low relevance. A total of 30 studies remained for literature review examination.

Of the 30 studies selected, a total of 27 studies examined risks of musculoskeletal disease (MSD) or injury to healthcare workers who manage patients with obesity. 13 studies documented potential medicolegal risks for healthcare organizations who treat patients with obesity and require staff to care for patients with obesity. 7 studies met the criteria for exploring the requirement for, or use of, data to quantify obese patient admission risks. Many papers identified multiple risk themes and each study included in the literature review is summarized in Table 3.

\section{Findings}

Obesity not only impacts the health of the individual, but it also results in high risks to healthcare organizations and staff. Similar to global obesity increases, patients with obesity being admitted to hospitals and attending emergency departments have also increased. ${ }^{5,6,15-17}$ Hospitalization of patients with obesity occurs due to a variety of factors, including the effects of comorbidities such as cardiac disease, diabetes and respiratory problems, and bariatric surgery for weight loss. Due to high clinical risks of obesity and the variety of testing and clinical procedures required, considered management of patients with obesity is required throughout the hospital journey from emergency departments, wards, radiography, theatres, physiotherapy and potentially the morgue.

\section{Bariatric Patient Handling Risks to Carers}

Managing patients with obesity results in increased physical workloads for carers, with high percentages of patients with obesity requiring assistance with bathing, toileting, repositioning and getting out of bed. ${ }^{18}$ The exertion, awkward postures and spinal loads experienced by carers who conduct these tasks result in high risk of injuries, which is further exacerbated by increased patient weight. ${ }^{5,11,18}$ The morbidly obese can also have significant width, causing carer injuries due to over-reaching.

Bariatric patient handling tasks present unique challenges and increased risks to carers as patient bodies are not uniform, body shape and weight is unevenly distributed and there are no convenient handholds to grasp. ${ }^{5}$ Additional patient challenges that increase caregiver risks include pain levels, immobility, levels of sedation and lack of cooperation. ${ }^{13}$ Bariatric patients require more frequent repositioning than normal weighted patients to prevent 


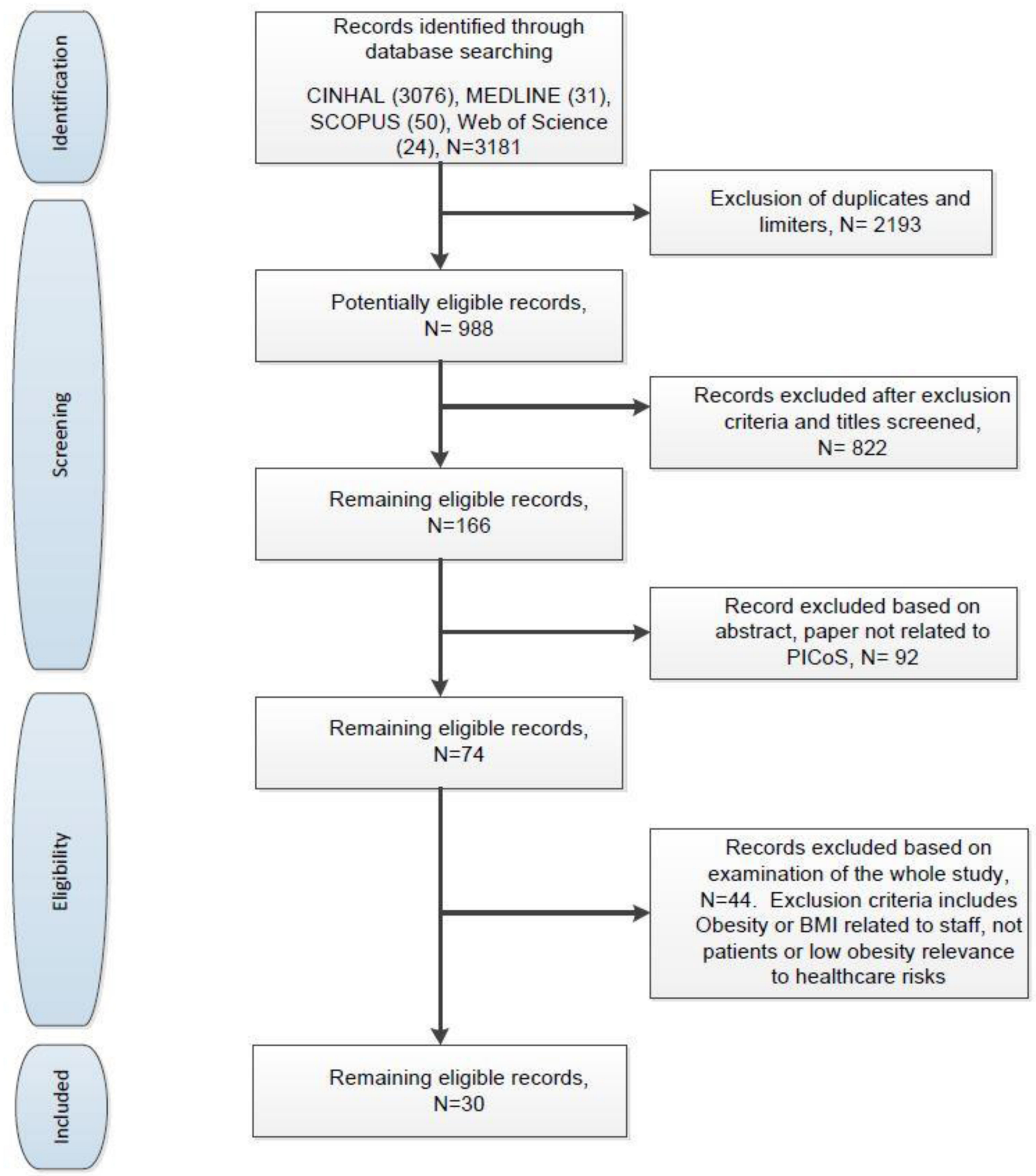

Figure I PRISMA study flow diagram.

Note: Adapted from from Moher D, Liberati A, Tetzlaff J, Altman DG. Preferred reporting items for systematic reviews and meta-analyses: the prisma statement. International journal of surgery. 20I0;8(5):336-34I. doi:I0.1016/j.jjsu.2010.02.007.

pressure ulcers, avoid respiratory issues and assist wound healing. ${ }^{5}$

Caring for patients with obesity is more labor intensive and requires more time, staff and specialist patient- handling skills and solutions. ${ }^{6,19}$ An additional 1.5 hours of care per day can be required when managing unconscious obese patients or patients requiring full care compared to normal weighted patients, and caregiver fatigue 
Table 3 Summary of the Studies Included in the Literature Review

\begin{tabular}{|c|c|c|c|}
\hline & Author (Year) & Risk & Key Findings and Recommendations \\
\hline I & Noel et al $(2010)^{32}$ & Data & $\begin{array}{l}\text { Anthropometric data (height, weight, BMI) are important and generally reliable } \\
\text { sources of obesity data. Recommendation: Anthropometric data can inform research } \\
\text { and development of obesity practices. Data completeness and quality can be } \\
\text { improved by Managers and Policy Makers. }\end{array}$ \\
\hline 2 & $\begin{array}{l}\text { Choi \& Brings } \\
(2016)^{16}\end{array}$ & MSD injury risks to staff. & $\begin{array}{l}\text { MSD risks to staff increased when conducting patient handling tasks on patients that } \\
\text { are overweight/obese. Recommendation: Patient-handling controls are required such } \\
\text { as lifting/transfer equipment, ergonomic assessments, no-lift policies and staff training. }\end{array}$ \\
\hline 3 & Chappell $(2007)^{30}$ & Medicolegal risk & $\begin{array}{l}\text { Claim increases relating to clinical negligence claims and staff injuries may occur if } \\
\text { obesity risk management is not implemented. Recommendation: Investment in clinical } \\
\text { and patient-handling equipment, and patient-handling training is required. }\end{array}$ \\
\hline 4 & Vieira $(2007)^{17}$ & MSD injury risks to staff. & $\begin{array}{l}\text { Transferring, turning and repositioning patients in bed are high-risk tasks to nurses, } \\
\text { and risks are magnified when managing patients with obesity. Recommendation: } \\
\text { Fitness for work, job modifications and training programs can reduce MSD risks to } \\
\text { nurses. }\end{array}$ \\
\hline 5 & $\begin{array}{l}\text { Cowley \& Leggett } \\
(2010)^{34}\end{array}$ & $\begin{array}{l}\text { Data, MSD injury risks to } \\
\text { staff. }\end{array}$ & $\begin{array}{l}\text { Staff manual handling risks are significant but not quantifiable. Risk is influenced by } \\
\text { environmental design, equipment limitations, training provision and use of written } \\
\text { procedures. Recommendation: Standardized definition of "bariatric". Increase } \\
\text { research to quantify bariatric patient movement in hospitals, funeral homes and } \\
\text { emergency services. }\end{array}$ \\
\hline 6 & $\begin{array}{l}\text { Davidson et al } \\
(2003)^{20}\end{array}$ & $\begin{array}{l}\text { Medicolegal risks, MSD } \\
\text { injury risks to staff. }\end{array}$ & $\begin{array}{l}\text { Medicolegal risks are high when treating patients with morbid obesity morbidly due } \\
\text { to size and weight difficulties. Organisational risks include patient-handling risks, } \\
\text { environmental modifications, and increased staff workloads and injury risks. } \\
\text { Recommendation: Planning to equip hospitals with resources to decrease body strain } \\
\text { will result in injury reduction. }\end{array}$ \\
\hline 7 & $\begin{array}{l}\text { Arzouman et al } \\
(2006)^{28}\end{array}$ & $\begin{array}{l}\text { Medicolegal risks, MSD } \\
\text { injury risks to staff. }\end{array}$ & $\begin{array}{l}\text { Physical injury may result when moving heavy patients, particularly to older nurses. } \\
\text { Inability to treat patients with obesity due to lack of bariatric equipment may create } \\
\text { legal issues. Recommendation: Nurses must be proactive in providing safe care to the } \\
\text { obese population. A bariatric protocol was successful which includes an } \\
\text { interdisciplinary approach, dissemination of information and staff training. }\end{array}$ \\
\hline 8 & $\begin{array}{l}\text { Galinsky, Hudock \& } \\
\text { Streit }(2010)^{5}\end{array}$ & $\begin{array}{l}\text { Data, MSD injury risks to } \\
\text { staff. }\end{array}$ & $\begin{array}{l}\text { Increasing overweight/obese patients are resulting in increased injuries to staff } \\
\text { conducting patient handling. Patients with obesity require more frequent and } \\
\text { extensive care, which involves increased time and physical exertion by staff. } \\
\text { Incomplete recoding of bariatric patient handling injuries occurs. Recommendation: } \\
\text { Research is needed to quantify bariatric patient-handling hazards/injuries and } \\
\text { assessment of ergonomic interventions. }\end{array}$ \\
\hline 9 & Morley $(2019)^{15}$ & MSD injury risks to staff. & $\begin{array}{l}\text { Increasing patients with obesity translates to increased obese deceased patients. } \\
\text { There is a lack of literature on safe management of deceased patients with obesity, } \\
\text { and patients are being manually handled post-death. Recommendation: Development } \\
\text { of a Deceased Bariatric Pack to reduce manual handling of deceased obese patients. }\end{array}$ \\
\hline 10 & $\begin{array}{l}\text { Labreche, Tucker \& } \\
\text { Kleinclaus. }(2017)^{33}\end{array}$ & $\begin{array}{l}\text { Medicolegal risk, MSD } \\
\text { injury risks to staff. }\end{array}$ & $\begin{array}{l}\text { Reductions in length of stay, case costs and patient/staff risks can result from use of } \\
\text { correct equipment, motivated patients with obesity and consistent and creative } \\
\text { rehabilitation teams. Recommendation: Bariatric cases reviews considering } \\
\text { improvement opportunities such as equipment and technology gaps. Knee pain } \\
\text { management should be considered for bariatric cases. }\end{array}$ \\
\hline
\end{tabular}

(Continued) 
Table 3 (Continued).

\begin{tabular}{|c|c|c|c|}
\hline & Author (Year) & Risk & Key Findings and Recommendations \\
\hline II & Van Wicklin $(2018)^{21}$ & $\begin{array}{l}\text { Medicolegal risk, MSD } \\
\text { injury risks to staff. }\end{array}$ & $\begin{array}{l}\text { Risks to patients with obesity and staff are present in operating rooms, including } \\
\text { increased risk of pressure injuries, venous thromboembolism (VTE), surgical } \\
\text { antisepsis, surgical positioning/movement and equipment. Recommendation: Identify } \\
\text { risks when moving patients and perioperative care. Implement interventions to } \\
\text { reduce pressure/positioning injuries and VTE, ensure supply of equipment and } \\
\text { personnel to move patients, and adhere to professional guidelines for safe surgical } \\
\text { positioning of patients with obesity. }\end{array}$ \\
\hline 12 & Gallagher $(2005)^{35}$ & $\begin{array}{l}\text { Medicolegal risk, MSD } \\
\text { injury risks to staff. }\end{array}$ & $\begin{array}{l}\text { Equipment for patients with obesity can improve quality of care, reduce length of stay } \\
\text { and be safer for staff to care for patients. Hospitals are at increased legal risk when } \\
\text { managing patients with obesity. Recommendation: Examine costs of staff injuries and } \\
\text { prolonged patient hospitalization to economically justify purchasing bariatric } \\
\text { equipment. Staff education, pre-planning, proper equipment and awareness of legal } \\
\text { implications will improve clinical and cost outcomes when managing patients with } \\
\text { obesity. }\end{array}$ \\
\hline 13 & Muir et al $(2007)^{6}$ & $\begin{array}{l}\text { Data, MSD injury risks to } \\
\text { staff. }\end{array}$ & $\begin{array}{l}\text { Lack of data measuring bariatric patients and patient-handling risks. Enhanced } \\
\text { bariatric patient process included staff training, equipment and patient handling policy. } \\
\text { Recommendation: Hospitals should assess bariatric equipment based on patient fit } \\
\text { not weight limits. Regular training and policies are required. Bariatric learnings and } \\
\text { improvements to be shared between hospitals. }\end{array}$ \\
\hline 14 & $\begin{array}{l}\text { Cowley \& Leggett } \\
(2011)^{26}\end{array}$ & $\begin{array}{l}\text { Data, MSD injury risks to } \\
\text { staff. }\end{array}$ & $\begin{array}{l}\text { Lack of understanding of bariatric risks across the patient care journey. Lack of } \\
\text { a standardized 'bariatric' definition including varied measurement of obesity. } \\
\text { Recommendation: Improved collaboration between patient industries to improve risk } \\
\text { reduction interventions. Standardized definition of 'bariatric' and improved data } \\
\text { collections to quantify bariatric frequency. }\end{array}$ \\
\hline 15 & Todd $(2009)^{36}$ & MSD injury risks to staff. & $\begin{array}{l}\text { Patients with morbid obesity incur } 81 \% \text { more healthcare costs than normal weighted } \\
\text { patients. Treating patients with obesity results in increased workload, resource } \\
\text { requirements, and staff safety issues. Recommendation: Hospitals must adapt to } \\
\text { accommodate patients with obesity. }\end{array}$ \\
\hline 16 & Swann $(2010)^{37}$ & MSD injury risks to staff. & $\begin{array}{l}\text { Risk assessments prior to patient admission should be conducted on obese patient- } \\
\text { handling and equipment needs. Training, equipment and sufficient working space is } \\
\text { required. Recommendation: Bariatric equipment must be suitable for patient size/ } \\
\text { weight, staff to be trained in equipment use and patient-handling procedures. }\end{array}$ \\
\hline 17 & $\begin{array}{l}\text { Richardson and Harris } \\
(2018)^{8}\end{array}$ & $\begin{array}{l}\text { Medicolegal risk, MSD } \\
\text { injury risks to staff. }\end{array}$ & $\begin{array}{l}\text { Patients with obesity are more likely to attend Emergency Department and have } \\
\text { higher health risks due to comorbidities. Challenges of treating patients with obesity } \\
\text { include difficulties with patient airways, circulation, radiographic imaging and } \\
\text { medication administration. Recommendation: Ongoing obesity management training, } \\
\text { including review of best practices, and patient handling. }\end{array}$ \\
\hline 18 & Whipple $(2008)^{23}$ & MSD injury risks to staff. & $\begin{array}{l}\text { Underutilization of bariatric equipment occurs despite awareness of increased staff } \\
\text { safety. Barriers to improving equipment use include commitment to traditional } \\
\text { practices, lack of staff training on equipment use and patient rehabilitation concerns. } \\
\text { Recommendation: Increased bariatric patient admissions will require improved } \\
\text { bariatric patient handling, including use of bariatric equipment. }\end{array}$ \\
\hline
\end{tabular}

(Continued) 
Table 3 (Continued).

\begin{tabular}{|c|c|c|c|}
\hline & Author (Year) & Risk & Key Findings and Recommendations \\
\hline 19 & Gallagher $(20 \mathrm{II})^{13}$ & $\begin{array}{l}\text { Medicolegal risk, MSD } \\
\text { injury risks to staff. }\end{array}$ & $\begin{array}{l}\text { Obesity may affect preventative care outcomes, delays in diagnosis and interventions. } \\
\text { Increasing numbers of patients with obesity will increase risk of injuries to staff. } \\
\text { Recommendation: Enhanced care for the obese includes use of equipment, staff } \\
\text { training, size-appropriate rooms and increased staffing. Implementing no-lift strategies } \\
\text { or lift teams increases staff safety. }\end{array}$ \\
\hline 20 & Edlich et al $(2005)^{25}$ & MSD injury risks to staff. & $\begin{array}{l}\text { Nursing is a high-risk occupation for back injuries, primarily from lifting patients. Body } \\
\text { mechanics training is ineffective for safe patient handling, and "no lift" approaches are } \\
\text { required. Recommendation: Increased use of bariatric lifting equipment is required. } \\
\text { Medicare systems must be updated to reimburse costs of hospital lifting equipment. }\end{array}$ \\
\hline 21 & Walden et al $(2013)^{14}$ & $\begin{array}{l}\text { Medicolegal risk, MSD } \\
\text { injury risks to staff. }\end{array}$ & $\begin{array}{l}\text { Lift teams resulted in decreased patient-handling injuries to staff by } 38 \% \text {, increased } \\
\text { staff perception of safety, reduced patient pressure ulcers by } 43 \% \text { and reduced care } \\
\text { costs by } \$ 495,293 \text {. Recommendation: Consider linking programs that improve staff } \\
\text { safety with enhanced patient care outcomes. }\end{array}$ \\
\hline 22 & Randall et al (2009) ${ }^{\prime \prime}$ & MSD injury risks to staff. & $\begin{array}{l}\text { Patients with obesity account for }<10 \% \text { of patients; however, } 30 \% \text { of staff injuries } \\
\text { occurred when caring for a patient with obesity, mostly due to patient-handling tasks. } \\
\text { Recommendation: Proven and effective bariatric patient-handling systems should be } \\
\text { implemented to protect staff. }\end{array}$ \\
\hline 23 & $\begin{array}{l}\text { Randall, Pories \& } \\
\text { Lucas }(2010)^{38}\end{array}$ & $\begin{array}{l}\text { Medicolegal risk, MSD } \\
\text { injury risks to staff. }\end{array}$ & $\begin{array}{l}\text { Using patient-handling equipment can reduce staff injuries and improve patient care } \\
\text { and hospital finances. Recommendation: Engineering solutions can reduce staff MSD } \\
\text { risks and improve patient care. }\end{array}$ \\
\hline 24 & $\begin{array}{l}\text { Wilson \& Tyler } \\
(2006)^{22}\end{array}$ & MSD injury risks to staff. & $\begin{array}{l}\text { The use of bariatric equipment, processes, training and work practices can reduce } \\
\text { staff injuries and improve patient care outcomes. Recommendation: } \\
\text { A multidisciplinary approach that includes policies, implementation responsibilities, } \\
\text { compliance accountability and equipment. }\end{array}$ \\
\hline 25 & Humphreys $(2007)^{24}$ & MSD injury risks to staff. & $\begin{array}{l}\text { Manual patient handling of patients with obesity is unsafe and risks MSD injuries to } \\
\text { nurses. Recommendation: Organizations should provide safe working environments } \\
\text { through ergonomic research, no-lift policies and education. }\end{array}$ \\
\hline 26 & $\begin{array}{l}\text { Muir \& Heese, } \\
(2008)^{18}\end{array}$ & MSD injury risks to staff. & $\begin{array}{l}\text { Staff safety decisions should be based on bariatric guidelines and patient-handling } \\
\text { algorithms. Recommendation: Further research into bariatric patient-handling tools } \\
\text { and algorithms is required. Successful bariatric patient systems and improved use of } \\
\text { bariatric equipment should be shared amongst organizations. }\end{array}$ \\
\hline 27 & $\begin{array}{l}\text { Muir \& Archer-Heese } \\
(2009)^{9}\end{array}$ & $\begin{array}{l}\text { Medicolegal risk, MSD } \\
\text { injury risks to staff. }\end{array}$ & $\begin{array}{l}\text { An effective bariatric patient-handling program includes operational procedures, } \\
\text { patient assessment tools, communication tools, patient-handling algorithms, space } \\
\text { and environment considerations, equipment needs, training and evaluation. } \\
\text { Recommendation: Timely procedure updating which incorporates ongoing bariatric } \\
\text { patient-handling research findings to ensure procedures are evidence-based and } \\
\text { reflect best practice. }\end{array}$ \\
\hline 28 & Kirk et al $(2010)^{29}$ & $\begin{array}{l}\text { Data, medicolegal risk, } \\
\text { MSD injury risks to staff. }\end{array}$ & $\begin{array}{l}\text { Height and pre-pregnancy weight is recorded; however, maternal obesity is not } \\
\text { regularly captured. Maternal obesity impacts clinical complications and staff injuries. } \\
\text { Recommendation: Formal recording of BMI/maternal obesity will improve } \\
\text { understanding of patient and staff needs, including tracking of interventions. Lack of } \\
\text { obesity data justified use of self-reported data but not ideal. }\end{array}$ \\
\hline
\end{tabular}


Table 3 (Continued).

\begin{tabular}{|l|l|l|l|}
\hline & Author (Year) & Risk & Key Findings and Recommendations \\
\hline 29 & Irwin $(2010)^{31}$ & Data, medicolegal risk & $\begin{array}{l}\text { Identifying and managing risks of obese pregnant patients is challenging; there are no } \\
\text { national guidelines to direct policy development. Recommendation: Risk management } \\
\text { approaches should be developed to safely manage obesity in pregnancy and improve } \\
\text { outcomes. Ongoing identification of maternal obesity and analysis of risk is required. }\end{array}$ \\
\hline 30 & Hahler (2002) & $\begin{array}{l}\text { Data, medicolegal risk, } \\
\text { MSD injury risks to staff. }\end{array}$ & $\begin{array}{l}\text { Obesity increases morbidity and mortality and causes numerous care challenges; } \\
\text { however, there are no data that quantify the extent of this problem and the effects of } \\
\text { targeted interventions. Recommendation: Research priorities are identification of } \\
\text { patients with obesity and measuring interventions. }\end{array}$ \\
\hline
\end{tabular}

relating to increased workloads and low recovery time between tasks may contribute to injuries. ${ }^{11,20}$ An unconscious patient with obesity may involve up to 5 staff to safely lift or reposition, and lack of staff availability in busy wards or smaller hospitals, during lunch breaks, shift changeovers or emergencies may also result in unsafe patient handling occurring. ${ }^{9,20,21,}$ High risk of injury also occurs when conducting bariatric nursing tasks that exceed safe working load limits such as changing patient dressings which involves elevating and supporting limbs weighing approximately $16 \%$ of an obese patient's total body weight. ${ }^{9}$ For a patient with obesity weighing 250 kilograms, changing a dressing may result in supporting 40 kilograms.

Nursing is one of the leading professions experiencing musculoskeletal injuries, and injuries to backs, wrists, knees and shoulders have increased when handling patients with obesity. ${ }^{14,16}$ A 2007 American study determined that during a 1-year period obese patients represented less than $10 \%$ of all patients however $30 \%$ of all carer injuries were due to bariatric patient handling. ${ }^{11}$ Patient obesity is known to be under-reported, and given the cumulative nature of patient handling injuries and community obesity increases, the true risk of handling patients with obesity is likely higher than reported and requires more investigation.

Managing patients with obesity while ensuring caregiver safety is a complex issue. Traditionally, patient handling techniques have been manual in nature and involved body mechanics and good lifting practices; however, a number of studies have found this training to be ineffective when lifting bariatric patients, even when conducting two-person lifts. $^{22-25}$ Alternatively, implementation of "lift teams" to move patients with obesity has been successful, decreasing carer injuries by $38 \%$, reducing workers' compensation claims by $62 \%$ and increasing staff job satisfaction and perceptions of organizational safety commitment. ${ }^{14,24}$

Although many healthcare organizations have implemented "no lift" policies that mandate staff to use equipment to lift and reposition patients, risks remain when conducting many bariatric tasks such as wound dressings, conducting physical therapy, surgical repositioning and bracing patient legs in maternity wards during birthing. Mandating the use of equipment and having a documented bariatric handling policy has reduced carer injuries. ${ }^{25,26}$ However, the supply of bariatric equipment alone presents challenges with staff reporting lack of training in equipment use, lack of awareness of equipment availability, perceptions that equipment is cumbersome or inconvenient, inability to locate equipment, time constraints and concerns that the equipment may not accommodate weight or size requirements. ${ }^{21,26}$

\section{Organizational Risks Relating to the Care of Obese Patients}

The above nursing challenges result in high risk of injury to carers and high liability risks to healthcare organizations who must care for and compensate injured staff. Organizations should consider the direct financial impact of workers' compensation costs and the human toll to staff that may include loss of physical function, loss of both short- and long-term income and risks to emotional health. ${ }^{14,25}$ Indirect organizational impacts to finances and resourcing also include injury investigations, increased overtime, hiring and training of replacement staff, replacement of staff wages, reduced efficiencies and increased management time requirements. ${ }^{25,27}$ Carers who have substantial injuries may also initiate common law claims that could be very costly to the organization. 
Risks relating to poor bariatric patient management may also impact an organization's culture and ability to retain staff. Healthcare workers report anxiety and safety concerns when managing patients with obesity, and organizations experience difficulties in recruiting and retaining staff in positions that include patient handling tasks. ${ }^{14,17,21,27}$ Edlich reports that back injuries may be the largest contributor to nursing shortages with $38 \%$ of nurses incurring back injuries during their career that required time off work and $12 \%$ of nurses resigning due to a back injury. ${ }^{25}$ Choi \& Brings and Edlich also assert that patient handling injuries are a major contributing factor to why nurses are leaving the profession, and that nursing workforce shortages have intensified due to occupational injuries. ${ }^{16,25}$ The increasing age of nurses, reduced employee functional fitness and increasing patients with obesity may all contribute to bariatric patient handling injuries. ${ }^{28}$ Fitness for work interventions for carers or role modifications may be required to reduce risks for both carers and organizations. ${ }^{17}$

Obesity also poses significant clinical care challenges when conducting physical assessments, positioning patients, drug dosing and accessing appropriate and safe equipment for diagnosis and treatment. ${ }^{29}$ A clinician's ability to physically assess and diagnose patients with obesity may be ineffective or inadequate due to increased skin folds obscuring affected areas, large abdomens, inability to locate anatomical landmarks, and difficulties in moving larger, heavier body parts. ${ }^{8,9,27}$ Obesity also affects standard procedures such as blood pressure assessments in that extreme size cuffs may be difficult to locate. $\mathrm{X}$-rays and MRIs may be impaired due to decreased image contrasts relating to obesity, and the equipment's ability to accommodate the patient's size and weight. ${ }^{8,13}$ Medication overdose or sub-therapeutic doses can also occur in obese patients due to body fat compositions and changes in metabolism. ${ }^{8}$

Increased hospital treatments, medical complications and length of stays often result in increased clinical workloads and hospital finances. Wounds of obese patients are often slower to heal and are at higher risk of infection. ${ }^{27}$ Loss of skin integrity and breakdown and development of pneumonia and pressure ulcers by obese patients delay recovery and add to hospital treatment costs. ${ }^{5,11}$

These challenges can result in increased risks of suboptimal care or adverse outcomes for patients, which may result in medical negligence cases. ${ }^{30}$ Clinical risks relating to maternal obesity and childbirth outcomes should also be considered by hospitals as they represent a significant portion of overall negligence claims. ${ }^{31}$ An organization's inability to care for patients with obesity due to lack of bariatric equipment or facilities may create legal risks that may be increasingly supported by legal arguments advocating for the same standards of care regardless of body size. ${ }^{13,28}$ While financial and legal risks are important considerations for organizations, the primary motivation for enhanced management of patients with obesity should be improved clinical care and staff safety, not protection from liability claims.

\section{Use of Data to Identify Patient Obesity and Quantify Associated Risks}

Hazard identification is one of the first principles of risk management, and obesity identification is a key factor in managing risks to healthcare organizations, workers and patients with obesity themselves. ${ }^{31}$ Anthropometric data including height and weight measurements are routinely collected during the patient's care and can be used to determine BMI and obesity. ${ }^{32}$ Although there is anecdotal recognition of increasing patients with obesity receiving healthcare, there are currently inadequate data to quantify obese patient treatment or admissions. ${ }^{27,29}$ Lack of obesity data recording and use often results in under-diagnosis of obesity; if obesity is not identified the patient is assumed to be of "normal" weight. ${ }^{32}$

Injuries to healthcare workers resulting from bariatric patient handling are also difficult to measure due to lack of patient obesity recording. ${ }^{5,6,26,27}$ Similarly, lack of obesity recording results in difficulties to measure targeted bariatric interventions. ${ }^{27}$ Hahler states the use of bariatric techniques and equipment is assumed to be effective; however, these assumptions are supported by anecdotal reporting and tradition. ${ }^{27}$ Increased obesity identification and recording will inform, measure and evaluate risk management strategies such as increased resourcing, bariatric equipment use and targeted interventions.

Challenges relating to obesity data recording are recognized, specifically lack of height recording which makes BMI calculations unattainable. Failure to record height is attributed to lack of measurement equipment, low perceived importance, time constraints, competing clinical demands, and difficulties in measuring patient populations who are bed or wheelchair-bound or amputees. ${ }^{32}$ Issues with obesity data accuracy can also occur, such as recording errors when obtaining measurements, during data entry or during data transfers between systems. ${ }^{32}$ Electronic data 
cleansing solutions can be utilized to identify data outliers and some inaccuracies, which will improve obesity data accuracy.

Despite known obesity data errors, organizations should consider the advantages of using anthropometric data if the errors are determined to be minimal and random. Evidence gained from the use of these available data will be cost and time effective and may outweigh the weaknesses in data accuracy. ${ }^{32}$ Increased support by healthcare managers and policymakers for improvements such as mandatory height and weight fields within electronic health records, clinical reminders and/or obesity recording performance measures will result in improved obesity data recording. Accurate identification of patients with obesity will also result in increased abilities to measure bariatric patient-handling hazards, related healthcare staff injuries and assess the effectiveness of bariatric interventions. ${ }^{5}$

\section{Limitations}

Although thorough search criteria were applied to the study reviews, there are limitations to this review that should be acknowledged. This review only included studies that were published in peer-reviewed journals in English. Therefore, some relevant literature in other languages or grey literature material has been excluded. Additionally, pediatric obesity was excluded from the search criteria; however, children with obesity are also recognized risk to healthcare staff, and more research on this topic is needed. Finally, risks of injuries due to bariatric patient handling and corresponding organizational risks are not limited to the healthcare industry. The identified risks should be considered by all industries that interact with people with obesity, such as aged care, funeral homes, ambulance services, and fire and emergency services.

\section{Conclusion}

This review examined risks to healthcare organizations and staff who manage patients with obesity and the use of data to identify and quantify obesity risks. Due to obligations to treat patients with obesity, risks cannot be eliminated however healthcare organizations can control risks when managing this patient cohort. The review resulted in recognition of increasing rates of patients with obesity requiring care however this appears to be anecdotal due to lack of obesity recording or use of available patient data. Similarly, hazards and injuries experienced by healthcare staff relating to bariatric patient-handling tasks are high and still under-reported and require data recording improvements to be implemented. Understanding bariatric patient-handling risks will help organizations to identify deficiencies in risk management systems and focus interventions and resources more precisely. $^{11}$

Moving patients with obesity, particularly the morbidly obese, presents high risks of injury to carers. Support and recognition of increased staff workloads and resourcing requirements when managing these patients are required by hospitals. Diverse risk management programs should also be implemented to reduce risks to carers, including using bariatric patient handling equipment, providing education and training; use of written procedures, considering environmental design, and bariatric patient risk assessments and individual care plans. ${ }^{26,30}$ "Lift teams" have also significantly reduced carer injuries and increasing staff job satisfaction and perceptions of organizational commitment to safety.

Clinical diagnoses and treatment of patients with obesity also present potential legal risks to organizations. Supplies of appropriate equipment and room to accommodate both a patient's weight and size to provide clinical care will be increasingly required, and the inability to provide care due to lack of facilities may result in discrimination complaints and legal action. While there may be high financial outlay to purchase the required equipment, implement bariatric risk management programs and ensure adequate medical facilities, without the right approaches, organizations are exposed to potentially significant adverse financial outcomes that include workers' compensation claims, common law claims and medical negligence claims.

Knowledge gaps exist relating to quantifying the requirement for obese healthcare, risks or injuries experienced by hospital staff and outcomes of bariatric patient handling interventions, and all risk categories require further examination. There is also a lack of published literature on the management of deceased obese patients, which also presents high risks to healthcare staff. Australian obesity projections demonstrate future increases in patients with obesity and more needs to be done to reduce risks to healthcare organizations, staff and patients.

\section{Disclosure}

The authors report no conflicts of interest or competing interests in this work.

\section{References}

1. World Health Organization. Preventing and managing the global epidemic: WHO obesity technical report series 894. Geneva, Switzerland; 2000. Available from: http://www.who.int/iris/handle/10665/42330. Accessed May 1, 2018. 
2. Australian Bureau of Statistics National Health Survey: First Results, 2017-18. ABS cat. no 4364. 0.55.001; 2018. Available from: https:// www.abs.gov.au/statistics/health/health-conditions-and-risks /national-health-survey-first-results/latest-release.

Accessed November 16, 2019.

3. Walls HL, Magliano DJ, Stevenson CE, et al. Projected progression of the prevalence of obesity in Australia. Obesity. 2012;20 (4):872-878. doi:10.1038/oby.2010.338

4. Pieracci F, Barie P, Pomp A. Critical care of the bariatric patient. Crit Care Med. 2006;34(6):1796-1804. doi: 10.1097/01. CCM.0000217216.84983.0A

5. Galinsky T, Hudock S, Streit J. Addressing the need for research on bariatric patient handling. Rehabil Nurs. 2010;35(6):242-247. doi:10.1002/j.2048-7940.2010.tb00054.x

6. Muir M, Heese GA, McLean D, Bodnar S, Rock B. Handling of the bariatric patient in critical care: a case study of lessons learned. Crit Care Nurs Clin North Am. 2007;19(2):223-240. doi:10.1016/j. ccell.2007.02.010

7. Australian National Preventative Health Agency Obesity: prevalence trends in Australia; 2014. Available from: http://sydney.edu.au/medi cine/research/units/boden/ANPHA\%20Obesity\%20Prevalence \% 20Trends.pdf. Accessed November 14, 2016.

8. Richardson S, Harris S. Managing the bariatric patient in the ED setting. Emerg Nurse. 2018;9-15.

9. Muir M, Archer-Heese G. Essentials of a bariatric patient handling program. Online J Issues Nurs. 2009;14(1):1.

10. Nelson AL; for Patient Safety Centre of Inquiry, Veterans Health Administration and Department of Defense. Patient care ergonomics guide: safe patient handling and movement; 2003. Available from: https:/osha.oregon.gov/edu/grants/train/Documents/va-patient-careergonomics-resource-guide-part-1-rev-8-2005.pdf. Accessed February 24, 2017.

11. Randall SB, Pories WJ, Pearson A, Drake DJ. Expanded occupational safety and health administration $300 \log$ as metric for bariatric patient-handling staff injuries. Surg Obes Relat Dis. 2009;5 (4):463-468. doi:10.1016/j.soard.2009.01.002

12. Graham P, Daugherty JP. Oh, their aching backs! Occupational injuries in nursing assistants. Orthop Nursing. 2012;31:218-223. doi:10.1097/NOR.0b013e31825dfd7a

13. Gallagher SM. Women's health, size, and safe patient handling: what are the ethical issues? Bariatr Nurs Surg Patient Care. 2011;6 (2):69-72. doi:10.1089/bar.2011.9973

14. Walden CM, Bankard SB, Cayer B, et al. Mobilization of the obese patient and prevention of injury. Ann Surg. 2013;258(4):646-650. doi:10.1097/SLA.0b013e3182a5039f

15. Morley S. Management of the deceased bariatric/obese patient. Int J SPHM. 2019;9(1):9-14.

16. Choi SD, Brings K. Work-related musculoskeletal risks associated with nurses and nursing assistants handling overweight and obese patients: a literature review. Work. 2016;53(2):439-448. doi:10.3233/ WOR-152222

17. Vieira ER. Why do nurses have a high incidence of low back disorders, and what can be done to reduce their risk? Bariatr Nurs Surg Patient Care. 2007;2(2):141-147. doi:10.1089/bar.2006.9975

18. Muir M, Heese GA. Safe patient handling of the bariatric patient: sharing of experiences and practical tips when using bariatric algorithms. Bariatr Nurs Surg Patient Care. 2008;3(2):147-158. doi:10.1089/bar.2008.9974

19. Todd M, Key M, Rice M, Salmon M. Moving and handling issues in the delivery of chronic oedema management. Br J Community Nurs. 2014;19:6-12. doi:10.12968/bjen.2014.19.Sup10.S6
20. Davidson JE, Kruse MW, Cox DH, Duncan R. Critical care of the morbidly obese. Crit Care Nurs Q. 2003;26(2):105-118. doi:10.1097/ 00002727-200304000-00005

21. Van Wicklin SA. Challenges in the operating room with obese and extremely obese surgical patients. Int J SPHM. 2018;8(3):120-131.

22. Wilson K, Tyler RD. Commentary. Ergonomics and the bariatric patient. Bariatr Nurs Surg Patient Care. 2006;1(3):173-178. doi:10.1089/bar.2006.1.173

23. Whipple KL. Maximizing healthcare provider safety while rehabilitating the bariatric patient. Bariatr Nurs Surg Patient Care. 2008;3 (1):41-45. doi:10.1089/bar.2008.9992

24. Humphreys SL. Obesity in patients and nurses increases the nurse's risk of injury lifting patients. Bariatr Nurs Surg Patient Care. 2007;2 (1):3-6. doi:10.1089/bar.2006.9998

25. Edlich RF, Hudson MA, Buschbacher RM, et al. Devastating injuries in healthcare workers: description of the crisis and legislative solution to the epidemic of back injury from patient lifting. J Long Term Eff Med Implants. 2005;15(2):225-241. doi:10.1615/ JLongTermEffMedImplants.v15.i2.90

26. Cowley SP, Leggett S. Manual handling risks associated with the care, treatment and transportation of bariatric (severely obese) clients in Australia. Work. 2011;39(4):477-483. doi:10.3233/WOR-20111197

27. Hahler B. Morbid obesity: a nursing care challenge. Medsurg Nursing. 2002;11(2):85-90.

28. Arzouman J, Lacovara JE, Blackett A, McDonald PK, Traver G, Bartholomeaux F. Developing a comprehensive bariatric protocol: a template for improving patient care. Medsurg Nursing. 2006;15 (1):21-26.

29. Kirk SF, Cramm CL, Price SL, Penney TL, Jarvie L, Power H. The state of obesity management for women giving birth in Atlantic Canada. Matern Child Health J. 2010;14(3):453-458. doi:10.1007/ s10995-009-0455-4

30. Chappell J. Managing the clinical and medicolegal risks of obesity. Clin Risk. 2007;13(6):216-219. doi:10.1258/135626207782322293

31. Irwin J. Obesity, risk and the challenges ahead for midwives. $\mathrm{Br}$ J Midwifery. 2010;18(1):18-23. doi:10.12968/bjom.2010.18.1.45811

32. Noël PH, Copeland LA, Perrin RA, et al. VHA corporate data warehouse height and weight data: opportunities and challenges for health services research. $J$ Rehabil Res Dev. 2010;47(8):739-750. doi:10.1682/JRRD.2009.08.0110

33. Labreche M, Tucker K, Kleinclaus T. Case study: a 600-LB patient journey to walk after 3 years of immobility. Int J SPHM. 2017;7 (3):122-128.

34. Cowley SP, Leggett S. Manual handling risks associated with the care, treatment and transportation of bariatric patients and clients in Australia. Int J Nurs Pract. 2010;16(3):262-267. doi:10.1111/j.1440172X.2010.01839.x

35. Gallagher S. Caring for the child who is obese: mobility, caregiver safety, environmental accommodation, and legal concerns. Pediatr Nurs. 2005;31(1):17-25.

36. Todd M. Managing chronic oedema in the morbidly obese patient. British J Nurs. 2009;18(18):1120-1124. doi:10.12968/ bjon.2009.18.18.44557

37. Swann J. Breaking down barriers to bariatric care. Nurs Residential Care. 2010;12(7):330-336. doi:10.12968/nrec.2010.12.7.48511

38. Randall SB, Pories WJ, Lucas G. A Process for the selection of a patient handling ceiling lift manufacturer. J Radiol Nurs. 2010;29 (3):69-74. doi:10.1016/j.jradnu.2010.05.001 


\section{Publish your work in this journal}

The Journal of Multidisciplinary Healthcare is an international, peerreviewed open-access journal that aims to represent and publish research in healthcare areas delivered by practitioners of different disciplines. This includes studies and reviews conducted by multidisciplinary teams as well as research which evaluates the results or conduct of such teams or healthcare processes in general. The journal covers a very wide range of areas and welcomes submissions from practitioners at all levels, from all over the world. The manuscrip management system is completely online and includes a very quick and fair peer-review system. Visit http://www.dovepress.com/testimonials. php to read real quotes from published authors. 